\title{
Variability in starch granular morphology of Tinospora cordifolia: an important species of Indian Systems of Medicine (ISM)
}

\author{
Aarti Kavane $^{1} \cdot$ Ashok Kumar Bishoyi $^{1,2} \cdot$ Anjali Sharma $^{1} \cdot$ Narendra Gajbhiye $^{1} \cdot$ K. A. Geetha ${ }^{1}$ \\ Received: 16 November 2020 / Revised: 3 August 2021 / Accepted: 6 August 2021 / Published online: 15 September 2021 \\ (c) Society for Plant Research 2021
}

\begin{abstract}
Tinospora cordifolia is an important medicinal plant species known for therapeutic action of starch along with other medicinal ingredients. The starch prepared from the aqueous extract of fresh stems is used in the Indian Systems of Medicines. The plant extract prepared from T. cordifolia is a promising source for the treatment of COVID-19. This investigation explores for the first time, the morphological details of the starch granules and its accumulation pattern along with its variability among the germplasm of T. cordifolia collected from different parts of India. Starch content was $39.80 \%$ on dry weight basis and moisture content was about $28.21 \%$. Starch granule recovery based on stem dry weight and starch content ranged from 14.70 to $20.28 \%$ and 52.02 to $71.76 \%$, respectively in different starch settling methods. Starch accumulation pattern in the stem was also studied in the species. Even though wide variability in starch granule shapes was observed among the germplasm, majority of the genotypes had starch granules of round or oval shape. Similarly, starch granule size also varied greatly $(38.32-88.03 \mu \mathrm{m})$ within and among the genotypes. Significantly small sized starch granules $(p=0.05)$ were present in the genotype, IC 283650 and biggest $(p=0.05)$ starch granules were present in the genotype, IC 310610 . The information generated in the present study will have application in starch industry for the inclusion of $T$. cordifolia as an alternative source of starch in addition to its use in Traditional Systems of Medicine.
\end{abstract}

Keywords COVID-19 $\cdot$ Genotypes $\cdot$ Starch granule $\cdot$ Starch recovery $\cdot$ Tinospora cordifolia

\section{Introduction}

Starches are the most important polysaccharide reserve material in the plant kingdom and a lot of studies have been conducted on cereals including wheat, rice and corn and tuber crops including Dioscorea sp., yams, potato, cassava, etc. and are extensively used for various food and nonfood applications. However, plants yielding starch which are medicinally important have not been focussed by the researchers except in few species viz., Fritillaria species, Dioscorea (Wang et al. 2006, 2007a). All these reported studies were in medicinal plants which are important for smaller bioactive molecule ingredients viz., alkaloids, steroids, etc. and not for starches. T. cordifolia (Willd.) Hook $\mathrm{f}$.

K. A. Geetha

geethaka99@yahoo.com

1 ICAR- Directorate of Medicinal and Aromatic Plants Research, Boriavi, Anand 387310, Gujarat, India

2 Department of Microbiology, Marwadi University, Rajkot, Gujarat, India
\& Thoms (Family: Menispermaceae) is one such important Indian medicinal species known for the therapeutic action of the starch along with the other compounds present in it (Choudhary et al. 2013).

Tinospora cordifolia is a glabrous, deciduous perennial climber (Fig. 1A) widely distributed in India from the Himalayas down to southern part of Peninsular India. It is also found in Burma, Andamans and Sri Lanka (Kirtikar and Basu 1994). In India, the species is known as Amrita (denotes the rejuvenating power of the species), Guduchi or Giloe. The species is dioecious, however, appearance of female phase in staminate flowers was also reported (Geetha et al. 2007). Mature stem is mainly used for the medicinal purposes.

The plant is mentioned in Ayurveda (one of the Indian Systems of Medicine) as a constituent of several compound preparations, used in general debility, dyspepsia, fevers and urinary diseases. The stem is used mainly for the preparation of these formulations or drugs. The bitter principle presents in the drug showed anti-periodic, antispasmodic, anti-inflammatory, antipyretic and 
Fig. 1 Plant habit and starch accumulation pattern in $T$. cordifolia. A Habit of T. cordifolia; B Iodine stained transverse section (TS) of T. cordifolia tender stem showing initiation of starch granular deposit in the cortex area; Iodine stained TS of $T$. cordifolia mature stem showing $\mathbf{C}$ starch granule deposition in medullary ray and cortex region; D starch granule deposition in the pith region; E different starch accumulation patterns; F Eccentric type of starch granule in $T$. cordifolia; Scale bar: $\mathbf{A}=10 \mathrm{~cm}$; $\mathbf{B}-\mathbf{D}=100 \mu \mathrm{m} ; \mathbf{E}=1 \mathrm{~cm}$; $\mathbf{F}=20 \mu \mathrm{m}$
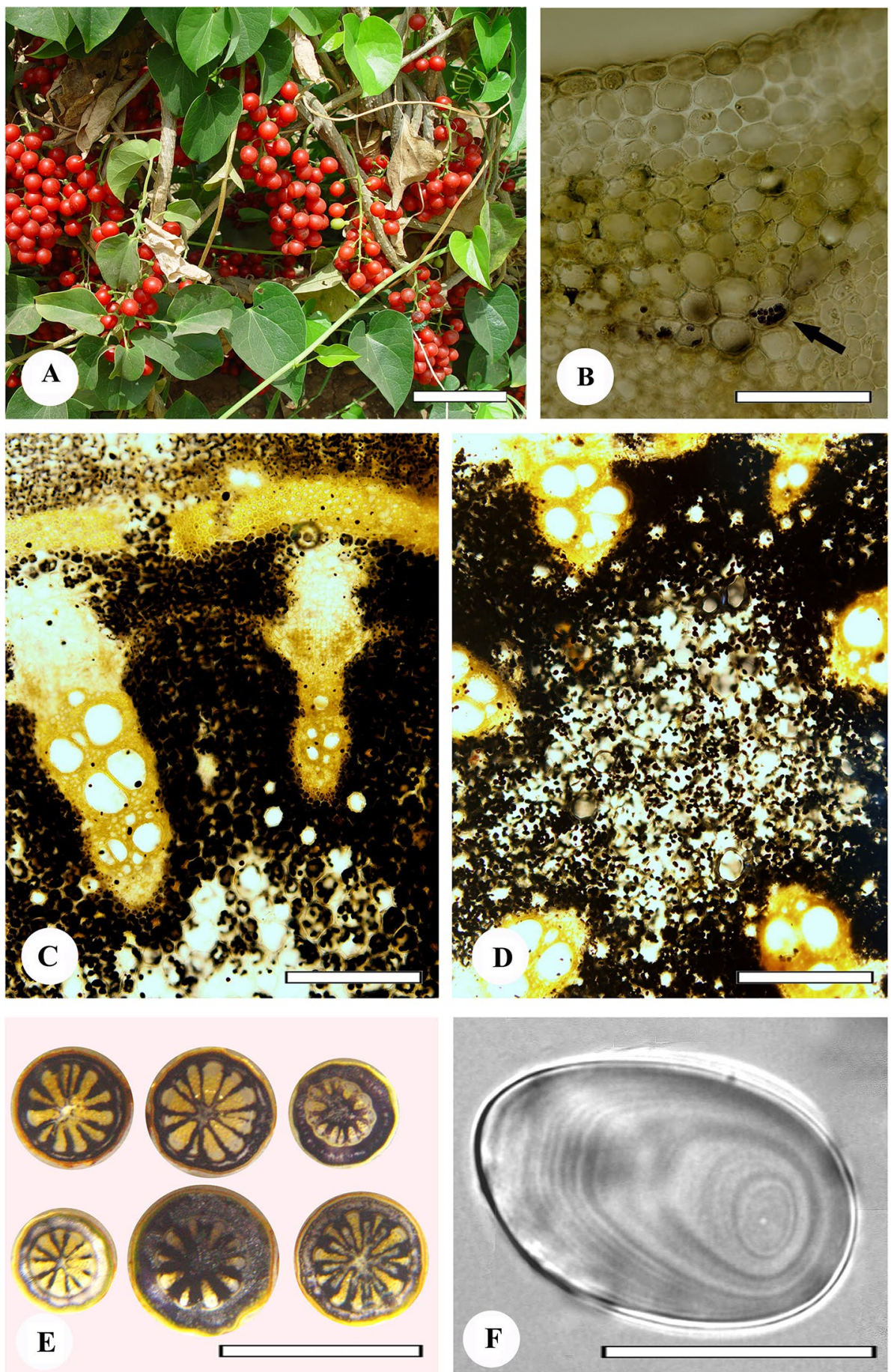

anti- microbial properties (Sharma et al. 2017). Chemical constituents of importance other than starch reported from this plant belong to alkaloids, diterpenoid lactones, glycosides, steroids, sesquiterpenoid, phenolics, aliphatic compounds and polysaccharides (Singh et al. 2003). Reports on pharmaceutical, morphological and chemical analysis showed that the plant not only has diversity in chemical constituents but also these constituents differ with respect to gender of the plant, geographical locations and harvesting seasons (Sharma et al. 2013a, b, c, d; 2015a, b). The therapeutic applications and notable medicinal properties reported are anti-diabetic, anti-periodic, antispasmodic, anti-inflammatory, anti-arthritic, anti-oxidant, anti-allergic, anti-stress, anti-leprotic, anti-malarial, 
hepatoprotective, immune-modulatory and anti-neoplastic activities (Choudhry et al. 2013; Sharma et al. 2014; Sharma et al. 2015c; Usmani et al. 2015). The plant extract prepared from $T$. cordifolia can be used for the treatment of COVID-19. Antiviral activity of natural compound extracted from $T$. cordifolia against Novel Corona Virus (SARS-CoV-2) had been evaluated and promising result was recorded (Vellingiri et al. 2020; Vasanthkumar and Arun 2020).

The starch (Giloe-ka-sat or Guduchi satva) prepared from the aqueous extract of the dry stems is used as tonic and is indicated in several diseases causing debility. The starch obtained from Guduchi Satva (extract) is comprised of 1-4 linked glucan with occasionally branched points. It was also reported that medium sized stem had more guduchi satva than thin and thick sized stems (Sharma et al. 2012). However, detailed studies on the starch granules is lacking in the species. Hence the present study reports for the first time, the accumulation pattern and morphological details of the starch granules and its variability among the germplasm of T. cordifolia collected from different parts of India.

\section{Materials and methods}

ICAR-Directorate of Medicinal and Aromatic Plants Research (ICAR-DMAPR), Anand, Gujarat, India is one of the National Active Germplasm Sites (NAGS) for conservation of Medicinal and Aromatic Plants (http://www.nbpgr. ernet.in/Downloadfile.aspx?EntryId=5764). Thirty-three genotypes collected from different natural habitats of the species in India which are conserved in the NAGS field gene bank of ICAR-DMAPR are used for the present study. The germplasm included 12 females and 21 males. Starch accumulation pattern, estimation and extraction were conducted in one of the selected genotype (IC 310601). Variability

Starch recovery (\%) based on starch content

$=\frac{\text { Weight of starch granules extracted by settling method (recovery) from the sample }(\mathrm{g})}{\text { Starch yield (starch estimated by anthrone method) in the same sample }(\mathrm{g})}$

$\times 100$

in starch granule shape and size was conducted in all the genotypes.

\section{Study on starch accumulation in the stem}

Starch accumulation pattern was studied for anatomical sections of freshly harvested stems. The study was carried out in the tender stem of about 1 month old to the mature stems

\section{Study of starch granules}

(1-year-old) for monitoring the initiation of starch granule accumulation. Freshly harvested stems were hand sectioned and stained with iodine solution (15 mg iodine flakes dissolved in $10 \mathrm{ml}$ ethanol) in a watch glass. Stained sections were placed on a micro-slide and observed under compound microscope (Olympus BX 50 equipped with camera (Olympus DP 71) and image analyser software Image Pro Express 6.0) and also under stereo microscope (Zeiss Stemi-2000C equipped with Axiocam MRC camera). Digital photomicrographs were taken from the study.

\section{Starch estimation and recovery}

Starch content was estimated by Anthrone method (Sadasivam and Manickam 1992) and expressed in percentage on dry weight basis. Dried stem powder of about $500 \mathrm{mg}$ was used for starch estimation $(n=10)$. Presence of mucilage is a major hurdle in extracting the starch granules in Tinospora. Hence different starch extracting media were compared for a better starch recovery in the species viz., $1 \%$ Calcium hydroxide solution, 0.03 M Ammonia water and chilled water (Moorthy 1990; Moorthy and Nair 1989) along with tap water (at ambient temperature) as control. About $200 \mathrm{~g}$ of fresh stem samples were used with five replications. The fresh stem samples were chopped into small pieces and ground in a mixercum-grinder and the ground mixture was soaked in different starch extraction media for $2 \mathrm{~h}$, with occasional stirring. The mixtures were filtered through a cotton cloth and the filtered solution was kept undisturbed for about $6 \mathrm{~h}$ for starch granular settling. The supernatant solution was drained out carefully. The sedimented starch portion was mixed with water, kept for starch granular sedimentation and supernatant was drained out. This was repeated thrice so that pure starch granules sedimented at the bottom.

Starch granules extracted from the fresh stems of 33 genotypes of $T$. cordifolia were used for the study. Care was taken to collect the stems of uniform maturity from all the genotypes. The extracted starch granules were stained with iodine solution and placed over micro-slides in a drop of glycerine. The granules were observed under compound microscope (Olympus BX 50 equipped with camera Olympus DP 71 and image analyser software Image Pro Express 
$6.0)$ at $40 \times$ magnification and digital photomicrographs were taken. Three slides per genotype were prepared and five fields were photographed in each slide for measurement of starch granular sizes. Starch granular size was measured (mean value of 50 readings were documented) using image pro express image analyser software. Starch granular diameter along the horizontal axis (L1) and perpendicular axis (L2) and perimeter were measured in each genotype. The replicated data collected from all the 33 genotypes were analysed by single factor ANOVA in complete randomized design (CRD). Based on the data on perimeter of the starch granules obtained from the studied genotypes, granules were categorized in to different size classes and genotypes were classified based on the frequency distribution of starch granules of different sizes.

\section{Results and discussion}

\section{Study on starch accumulation in stem}

Monitoring of starch accumulation in different growth stages of the stem revealed that starch deposition is initiated in the cortex area in the tender stems i.e., about 1 month old stems
(Fig. 1B) and in the mature stems (12-18 months old stems), starch deposition was noticed in the cortex, medullary rays and pith with no starch accumulation in the xylem region as revealed in the transverse sections of the stem stained with iodine (Fig. 1C-E). Invariably, starch granules were of eccentric type in the species (Fig. 1F).

\section{Starch estimation and recovery}

Starch content present in the studied genotype (IC 310601) was $39.80 \%$ ( $\mathrm{SD} \pm 4.44)$ on dry weight basis. Moisture content in the genotype was about $28.21 \%$. On fresh weight basis starch content was estimated as $11.23 \%$. Starch granule yield, based on dry weight basis of the stem varied from 14.70 to $20.28 \%$ in different starch extraction treatments. Highest starch granule yield was in chilled water extraction (20.28\%) followed by tap water and the lowest yield was in Calcium hydroxide solution. Ammonia solution could not enhance the starch sedimentation in the species (Table 1 and Fig. 2). Percentage of starch granule recovery based on starch content of the stem varied from 52.02 to $71.76 \%$ in different starch settling methods (Table 1 and Fig. 2). The study thus showed that chilled water or tap water can
Table 1 Starch granule yield and recovery in different starch granule settling methods in $T$. cordifolia

\begin{tabular}{lll}
\hline Extraction medium & $\begin{array}{l}\text { Starch granular yield (\%) based on } \\
\text { fresh stem weight basis }\end{array}$ & $\begin{array}{l}\text { Starch granular recovery } \\
(\%) \text { based on starch yield }\end{array}$ \\
\hline Chilled water & $8.07(2.84)^{\mathrm{a}}$ & $71.80^{\mathrm{a}}$ \\
Ammonia solution & $6.77(2.60)^{\mathrm{a}}$ & $60.23^{\mathrm{a}}$ \\
Calcium hydroxide solution & $5.85(2.41)^{\mathrm{b}}$ & $52.05^{\mathrm{b}}$ \\
Tap water (Control) & $7.11(2.66) \mathrm{a}$ & $63.26^{\mathrm{a}}$ \\
\hline
\end{tabular}

Values in parenthesis are squire root transformed values; Values which share common letter in superscript in a column are not significantly different $(\mathrm{P}<0.01)$
Fig. 2 Starch granule recovery in different starch settling methods

\section{- Starch granule yield based on dry wt basis of the stem (\%) \\ - Starch granule recovery based starch content (\%)}

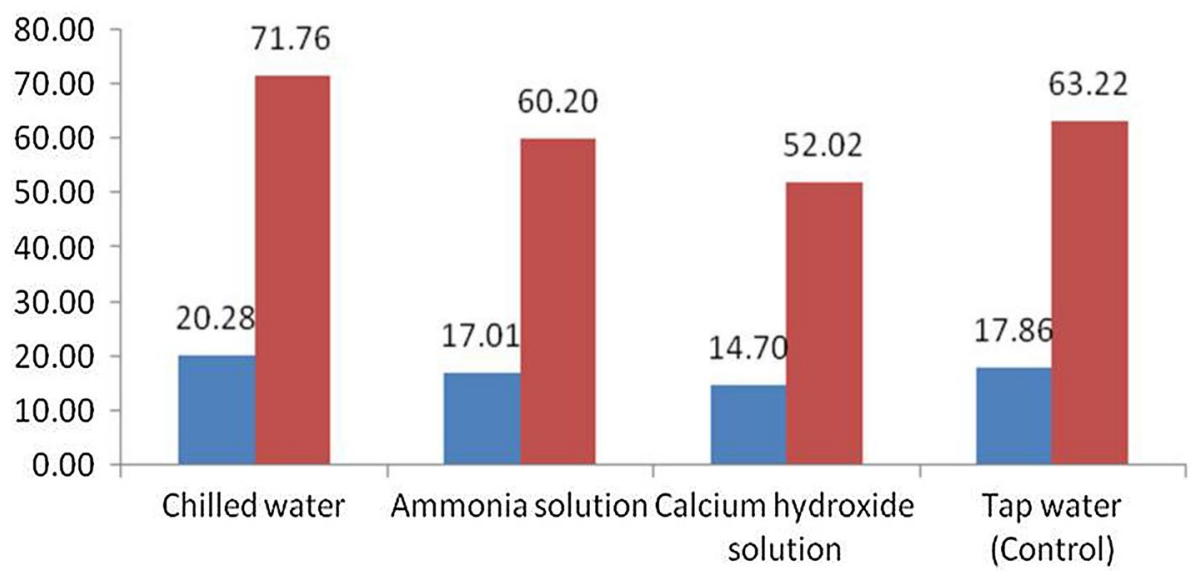


Fig. 3 Starch granular shape variability among the genotypes of T. cordifolia. A IC 283953;

B IC 293959; C IC 310608;

D: NRC TC1; Scale bar

A-D $=100 \mu \mathrm{m}$

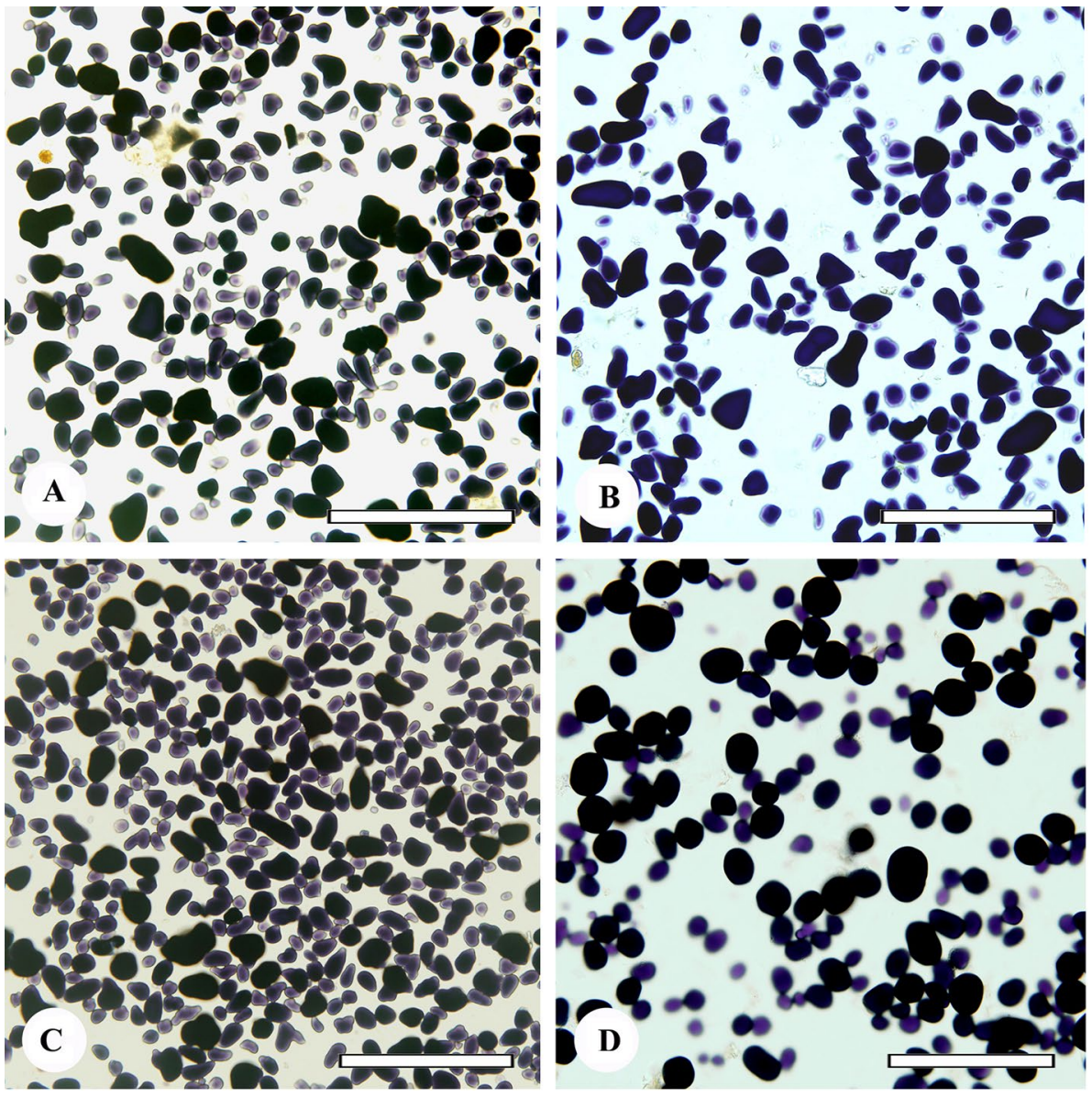

be effectively utilized in the species for large scale starch extraction.

\section{Study of starch granules}

Shape of the starch granules varied from round, oval, dumbbell, cylindrical, cylindrical with concave and convex surfaces to different non-specific shapes within and among different genotypes. However, majority of the granules were of round to oval in shape. IC 283953, IC 310608, IC 283959 and MPTC 1 showed highly variable shapes (Fig. 3A-C). NRC TC1 showed predominantly round shaped granules (Fig. 3D).

Similarly, starch granular size also varied significantly ( $p=0.05$ ) among the genotypes of $T$. cordifolia (Table 2 and Fig. 4A-D). Diameter (L1 and L2) ranged from 9.39 to $23.62 \mu \mathrm{m}$ and 12.49 to $29.05 \mu \mathrm{m}$, respectively among the different genotypes. Starch granular perimeter ranged from 38.32 to $88.03 \mu \mathrm{m}$ among the genotypes. Significantly smaller granules $(p=0.05)$ were present in IC 283650, a female genotype which was at par with MPTC 1 (Female), GUJ2 (Male), IC 310608 (Male) and GUJ3 (Male). IC 310610 (Female) had significantly bigger starch granule $(p=0.05)$, however, it was at par with genotypes IC 310602 (Male) and K95 (Male) (Table 2). There was no gender based size difference in starch granules among the studied genotypes. Gender based differences as reported in phytoconstituents in T. cordifolia (Wang et al. 2007b; Choudhary et al. 2013) was not observed in the present study.

Based on the range in the value of perimeter of the starch granules among the different genotypes, granules were classified as very small (those in the range of $15.00-45.00 \mu \mathrm{m}$ ), small (those in the range of 46.00-75.00 $\mu \mathrm{m}$ ), medium (those in the range of 76.00-105.00 $\mu \mathrm{m}$ ), big (those in the range of 106.00-135.00 $\mu \mathrm{m}$ ) and very big (those in the range of 136.00-165.00 $\mu \mathrm{m}$ ) (Table 3). However, within a genotype, there were different size grades of starch granules. Hence, depending upon the predominance of starch granular sizes present in a genotype (if $>50 \%$ of starch granules), the genotypes also were categorized into five groups i.e., very small, small, medium and big and very big. Majority of the studied genotypes were having small starch granules i.e., granule size was having perimeter ranged from 46 to $75 \mu \mathrm{m}, \mathrm{L} 1$ ranged from 10 to $25 \mu \mathrm{m}$ and $\mathrm{L} 2$ ranged from 10 to $20 \mu \mathrm{m}$. Even though, there were starch granules of big and very big sizes, their frequency within a genotype was very low and 
Table 2 Measurements of starch granule size among different genotypes of $T$. cordifolia

\begin{tabular}{|c|c|c|c|c|c|}
\hline & Genotypes & $\mathrm{L} 1(\mu \mathrm{m})$ & $\mathrm{L} 2(\mu \mathrm{m})$ & Perimeter $(\mu \mathrm{m})$ & $\begin{array}{l}\text { Range of perimeter } \\
(\mu \mathrm{m}) \text { within the geno- } \\
\text { types }\end{array}$ \\
\hline 1. & IC $283650-F$ & $9.90^{\text {opqr }}$ & $12.31^{\mathrm{s}}$ & $38.32^{\mathrm{op}}$ & $24.83-62.98$ \\
\hline 2. & IC 283651-M & $16.26^{\mathrm{efgh}}$ & $20.89^{\text {efghijkl }}$ & $63.55^{\text {efghijk }}$ & $41.70-107.15$ \\
\hline 3. & IC 283652-M & $14.60^{\mathrm{ghijk}}$ & $20.27^{\text {ghijklmn }}$ & $59.66^{\text {efghijk }}$ & $33.88-96.66$ \\
\hline 4. & IC $283950-\mathrm{F}$ & $16.00^{\text {efghi }}$ & $21.61^{\text {cdefghi }}$ & $64.56^{\text {defghij }}$ & $31.46-118.70$ \\
\hline 5. & IC $283950-\mathrm{M}$ & $15.68^{\text {efgh }}$ & $22.14^{\text {cdefghi }}$ & $59.49^{\text {defghi }}$ & $36.60-78.13$ \\
\hline 6. & IC $283953-F$ & $16.90^{\mathrm{defg}}$ & $24.25^{\text {bcdefg }}$ & $69.40^{\text {bcde }}$ & $43.32-116.01$ \\
\hline 7. & IC 283954-F & $12.71^{\mathrm{ijklmn}}$ & $18.67^{\mathrm{ijklmnopq}}$ & $54.14^{\text {ghijkl }}$ & $32.79-121.37$ \\
\hline 8. & IC 283955-F & $20.49^{b c}$ & $25.46^{\mathrm{abcd}}$ & $74.66^{\mathrm{bcd}}$ & $34.15-155.02$ \\
\hline 9. & IC 283959-M & $15.05^{\text {efgh }}$ & $20.75^{\text {fghijklm }}$ & $69.40^{\text {defghijk }}$ & $44.90-97.00$ \\
\hline 10. & IC 283962-M & $18.88^{\text {fghijk }}$ & $24.97^{\text {abcde }}$ & $78.06^{\text {bcdef }}$ & $45.74-115.26$ \\
\hline 11. & IC 285624-M & $14.85^{\text {fghijk }}$ & $17.65^{\mathrm{jklmnopq}}$ & $58.87^{\text {efghijk }}$ & $38.74-111.32$ \\
\hline 12. & IC 310601-M & $14.47^{\text {fghijk }}$ & $19.45^{\text {hijklmnop }}$ & $54.87^{\mathrm{hijkl}}$ & $42.37-70.16$ \\
\hline 13. & IC 310602-M & $19.96^{\text {bcd }}$ & $26.03^{\mathrm{abc}}$ & $80.47^{\mathrm{ab}}$ & $52.06-128.37$ \\
\hline 14. & IC 310605-M & $12.98^{\mathrm{jklmn}}$ & $16.75^{\mathrm{mnopqr}}$ & $53.46^{\mathrm{ijklm}}$ & $36.64-82.43$ \\
\hline 15. & IC 310608-M & $9.39^{\text {opqr }}$ & $14.90^{\mathrm{qrs}}$ & $43.34^{\text {mnop }}$ & $20.03-77.03$ \\
\hline 16. & IC 310610-F & $23.62^{\mathrm{a}}$ & $29.01^{\mathrm{a}}$ & $88.03^{\mathrm{a}}$ & $58.87-123.43$ \\
\hline 17. & IC 310621-F & $13.69^{\mathrm{hijklm}}$ & $18.95^{\mathrm{ijklmnopq}}$ & $56.85^{\text {fghijkl }}$ & $33.80-86.18$ \\
\hline 18. & K 88-M & $14.34^{\text {ghijkl }}$ & $21.45^{\text {defghijk }}$ & $63.68^{\text {defghijk }}$ & $44.85-91.67$ \\
\hline 19. & K 95-M & $18.18^{\text {bcde }}$ & $26.70^{\mathrm{ab}}$ & $78.89^{\mathrm{abc}}$ & $57.26-107.92$ \\
\hline 20. & HYD1-F & $15.98^{\text {efghi }}$ & $24.77^{\text {bcdef }}$ & $70.82^{\text {bcde }}$ & $33.50-104.49$ \\
\hline 21. & HYD 2-M & $11.64^{\mathrm{lmnopqr}}$ & $17.44^{\mathrm{klmnopq}}$ & $52.85^{\text {jhijklm }}$ & $12.08-86.54$ \\
\hline 22. & WB $1 \mathrm{M}$ & $15.70^{\text {efghi }}$ & $20.41^{\text {ghijklmn }}$ & $62.46^{\text {efghijk }}$ & $41.79-90.69$ \\
\hline 23. & NRC TC1M & $20.88^{\mathrm{b}}$ & $21.78^{\text {defghi }}$ & $68.47^{\text {cdefg }}$ & $51.79-85.38$ \\
\hline 24. & GUJ1-M & $16.21^{\mathrm{efgh}}$ & $20.91^{\text {efghijkl }}$ & $63.34^{\text {defghijk }}$ & $30.03-156.64$ \\
\hline 25. & GUJ2-M & $11.15^{\mathrm{mnopqr}}$ & $13.28^{\mathrm{rs}}$ & $40.45^{\text {nop }}$ & $27.58-58.19$ \\
\hline 26. & GUJ 3-M & 9.57 & $16.39^{\text {nopqrs }}$ & $43.39^{\mathrm{lmnop}}$ & $15.60-78.80$ \\
\hline 27. & GUJ 4-F & $13.17^{\mathrm{ijk} \mathrm{lmn}}$ & $18.57^{\mathrm{ijklmnopq}}$ & $56.80^{\text {ghijkl }}$ & $36.58-72.11$ \\
\hline 28. & GUJ5-M & $12.06^{\mathrm{klmnopq}}$ & $17.05^{\text {Imnopqr }}$ & $51.89^{\text {jhijklm }}$ & $37.76-74.61$ \\
\hline 29. & GUJ 6-F & $17.88^{\text {cde }}$ & $23.28^{\text {bcdefgh }}$ & $70.60^{\text {bcde }}$ & $41.98-107.82$ \\
\hline 30. & NMRM 13-M & $17.03^{\mathrm{klmnop}}$ & $17.17^{\mathrm{lmnopqr}}$ & $51.52^{\mathrm{klmn}}$ & $33.61-86.03$ \\
\hline 31. & NMRM 14-M & $10.96^{\text {nopqr }}$ & $15.61^{\text {opqrs }}$ & $46.64^{\operatorname{lmnop}}$ & $35.45-63.29$ \\
\hline 32. & NMRM 16-F & $17.47^{\mathrm{def}}$ & $22.25^{\text {cdefghi }}$ & $65.55^{\mathrm{defgh}}$ & $38.38-126.96$ \\
\hline 33. & MPTC 1-F & $10.25^{\mathrm{opqr}}$ & $17.07^{\text {lmnopqr }}$ & $38.39^{\text {mnop }}$ & $26.00-58.78$ \\
\hline
\end{tabular}

$M$ male, $F$ female; value's which share common letter in superscript in a column are not significantly different $(\mathrm{P}<0.05)$ none of the genotypes studied presently represented these classes (Fig. 5).

The granule size distribution and shape are considered important for the functional properties of the starch. Starch granules of different sizes have different physical, chemical, and functional properties (Chiotelli et al. 2002; Park et al. 2005). It has been documented that granule size distribution varies between cultivars, suggesting considerable genetic control (Peterson and Fulchner 2001). Studies conducted in four Fritillaria species, F. thunbergii, F. ussurensis, F. pallidifloca and $F$. cirrhosa, showed that granule sizes of the former two Fritillaria starches ranged from 5 to $40 \mu \mathrm{m}$, and starch shape were cycloidal or elliptic-shaped; the latter two Fritillaria starch granules had granule sizes ranging from 5 to $50 \mu \mathrm{m}$, and the granule shape varied from oval to irregular or cuboidal (Wang et al. 2006, 2007a, b). In Diascorea nipponica also, studies showed that the starch sizes can be compared with tapioca $(6-31 \mu \mathrm{m})$ and potato starches (10-65 $\mu \mathrm{m})$, the morphology of starch granules showed smaller particles (3-22 $\mu \mathrm{m})$, oval shaped and dissimilar granular sizes (Jane et al. 1994; Yuan et al. 2007). In Curcuma longa starch, the predominant granule sizes were 20-25 $\mu \mathrm{m}$ and, for C. zedoaria, it was 20-30 $\mu \mathrm{m}$ and with shape of flat triangular. The average particle diameter of starch from different Dioscorea opposita Thunb. cultivars were 38.7-40.3 $\mu \mathrm{m}$ and the shape of starch granules varied 
Fig. 4 T. cordifolia genotypes showing variability in starch granular sizes. Smaller starch granules in A IC 283650 and $\mathbf{B}$ GUJ2; bigger granules in C IC 310610 and D K 95; Scale bar $\mathbf{A}-\mathbf{D}=50 \mu \mathrm{m}$
Table 3 Grouping of genotypes based on starch granular size grades

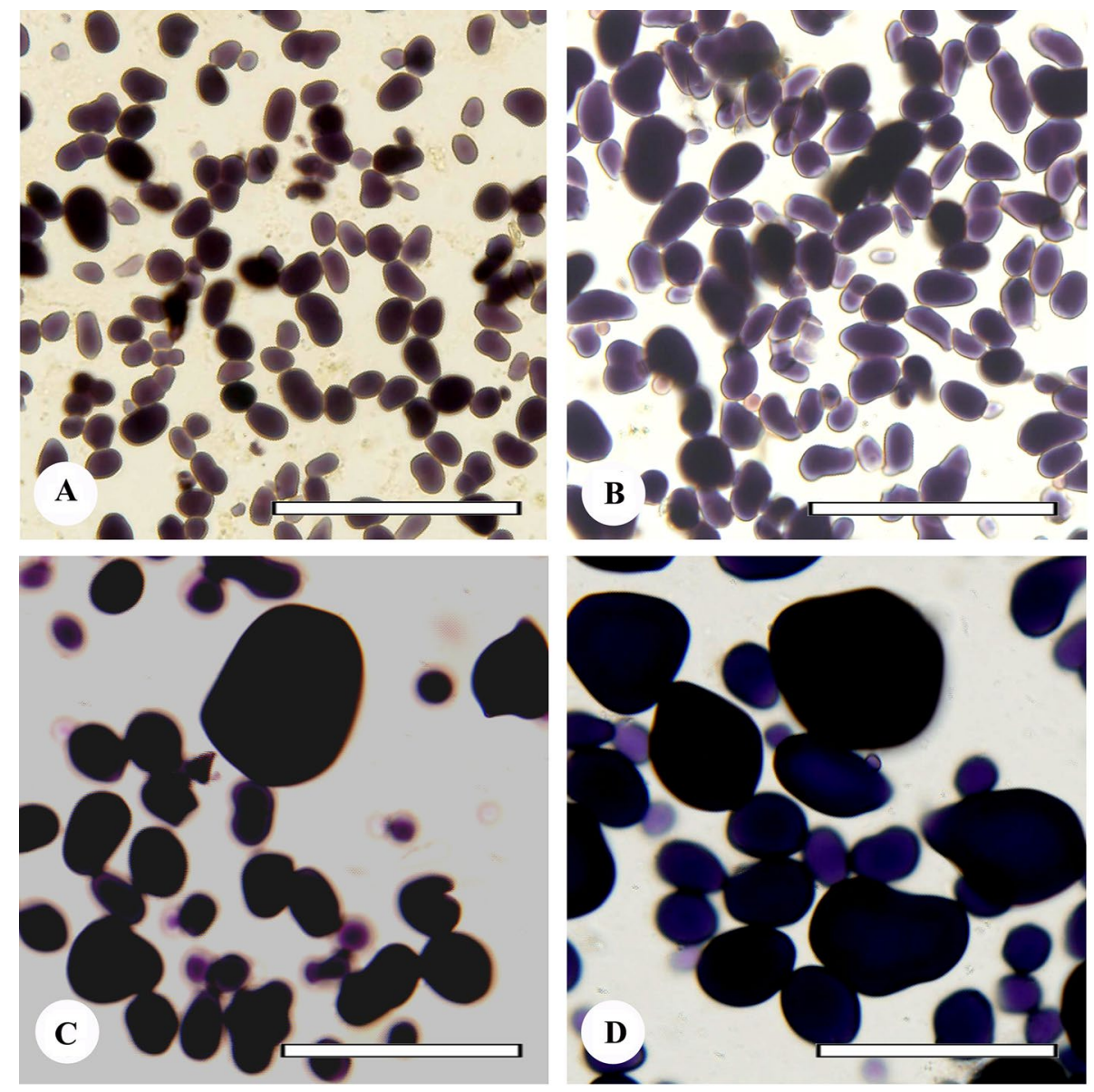

Starch granular size grades (Rang in $\mu \mathrm{m}$ )

\author{
Very small (15.00-45.00) \\ Small (46.00-75.00)
}

Medium (76.00-105.00)

Big (106.00-135.00)

Very big $136.00-165.00$

$M$ male, $F$ female from round to oval or irregular (Wang et al 2006, 2007a). In Lepidium meyenii, root starch granule shape showed oval and irregular morphology and size varied between 7.4 and $14.9 \mu \mathrm{m}$ in length and 5.8 and $9.3 \mu \mathrm{m}$ in diameter (Rondán and Finardi 2009; Wang et al. 2007b). The Operculina tuber$o s a$, starch granules were essentially polygonal, spherical and semi-spherical truncated forms and size varied in the ranges 9.2-19.5 $\mu \mathrm{m}, 11.5-3.0 \mu \mathrm{m}$ and $6.0-15.5 \mu \mathrm{m}$, respectively (Gomes et al. 2009).

Reports demonstrated the influence of the temperature variation in determining the starch granule size in sweet potato, wheat and maize and have observed the decrease in size and consequently, change the starch granules' physical-chemical (Lu et al. 1996; Wang et al. 2007a). However, the variability in starch granular size within and among the $T$. cordifolia genotypes collected from the different parts of the country in the present study could not be correlated to the environmental influences, since they were grown under the same agro-climatic conditions. Genotypic/ cultivar influence on size and shape of the starch granules was previously reported in other crops also (Moorthy et al. 1990; Chiotelli et al. 2002; Leonel 
Fig. 5 Classification of T. cordifolia genotypes based on starch granule size

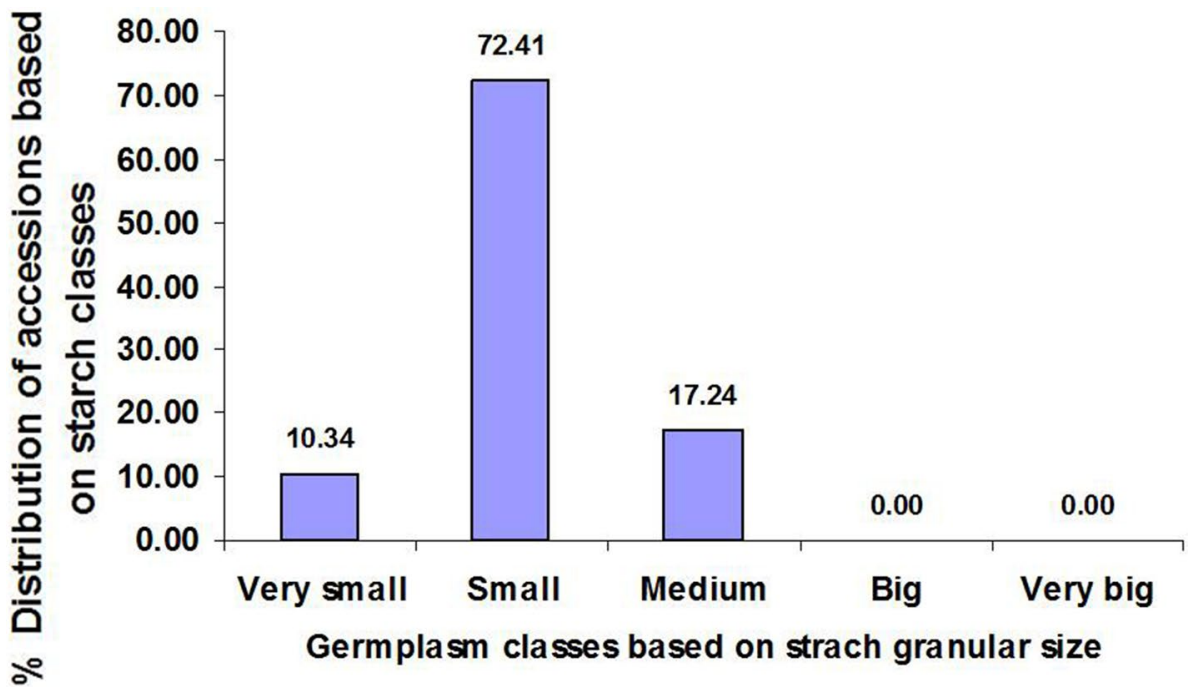

et al. 2003; Wang et al. 2007b). Separate study is required to prove the hypothesis of influence of environment on starch granular size in $T$. cordifolia.

Granule shape and size are also characteristic of a plant; they define mesh size for extraction and purification sieves and may influence the industrial application. Granule size is also very important since it influences the starch digestibility in various crops (Riley 2004). Hence the information generated in the present study will have application in starch industry for the inclusion of $T$. cordifolia as an alternative source of starch in addition to its use in Traditional Systems of Medicine.

\section{Conclusion}

The present study revealed the accumulation pattern and variability in morphology and starch granular sizes in $T$. cordifolia germplasm collected from different natural habitats of the species. Even though, there were shape variations in starch granules within and among the genotypes, majority of the genotypes had oval to round shaped starch granules. Similarly, starch granule size also varied greatly within and among the genotypes, however, majority of the genotypes studied were having small starch granules (in the range of 46.00-75.00 $\mu \mathrm{m}$ ). Percentage of starch granule recovery based on starch content of the stem varied from 52.02 to $71.76 \%$ in different starch settling methods. The study also revealed that chilled water or tap water (at ambient temperature) can be effectively utilized for large scale starch extraction. The information generated in the present study will have application in starch industry for the inclusion of $T$. cordifolia as an alternative source of starch in addition to its use in Traditional Systems of
Medicine. Work is in progress to collect more information for selection of genotypes suitable for therapeutic purposes and starch industry.

Supplementary Information The online version contains supplementary material available at https://doi.org/10.1007/s42535-021-00286-y.

Acknowledgements We would like to thank Dr. Satyabrata Maiti, Former Director, ICAR Directorate of Medicinal and Aromatic Plants Research for providing the facilities and also for encouragement to carry out this research.

\section{Declarations}

Conflict of interest The authors declare that they have no conflict of interest.

\section{References}

Chiotelli E, Martine Le Meste M (2002) Effect of small and large wheat starch granules on thermomechanical behavior of starch. Cereal Chem 79:286-290

Choudhary N, Siddiqui MB, Azmat S, Khatoon S (2013) Tinospora cordifolia: ethnobotany, phytopharmacology and phytochemistry aspects. Int J of Pharm Sci Res 4:891-899

Geetha KA, Josphin M, Maiti S (2007) Gender instability in Tinospora cordifolia - an immunomodulator. Curr Sci 92:591-592

Gomes AMM, Silva PL, Soares SA, Silva CEM, Gallão MI, Germani $\mathrm{R}$, Ricardo NMPS (2009) Isolation and physico-chemical and rheological characterisation of the Brazilian jalap starch (Operculina tuberosa Meisn.). Carbohydr Polym 7:885-890

Jane JI, Kasemsuwan T, Leas S, La A, Zobel H, Robyt JF (1994) Anthology of starch granule morphology by scanning electron microscopy. Starch/ Stärke 46:121-129

Kirtikar ID, Basu BD (1994) Indian Medicinal Plants. Lalit Mohan Basu, India, pp78

Leonel M, Sarmento SBS, Cereda MP (2003) New starches for the food industry: Curcuma longa and Curcuma zedoaria. Carbohydr Polym 54:385-388 
Lu TJ, Jane J, Keeling PL, Singletary GW (1996) Maize starch fine structures affected by ear developmental temperature. Carbohydra Res 282:157-170

Moorthy SN (1990) Extraction of starches from tuber crops using Ammonia. Carbohydr Polym 91:391-398

Moorthy SN, Nair SG (1989) Studies on Dioscorea rotundata starch properties. Starch/starke 41:81-83

Peterson DG, Fulchner RG (2001) Variation in Minnesota HRS wheats: starch granule size distribution. Food Res Int 34:357-363

Riley CK (2004) In vitro digestibility of raw starches extracted from five Yam species grown in Jamaica. Starch/ Stärke 56:69-73

Rondán SGG, Finardi FF (2009) Physical-chemical and functional properties of maca root starch (Lepidium meyenii Walpers). Food Chem 114:492-498

Sadasivam S, Manickam A (1992) Biochemical methods, 2nd edn. New Age International Publishers, New Delhi

Sharma R, Prajapati PK (2017) Comparative antimicrobial screening of satva (sedimented starchy aqueous extract) and ghana (solidified aqueous extract) of Guduchi (Tinospora Cordifolia (Willd.) Miers). Innovare J Ayurvedic Sci 5:1-4

Sharma R, Harisha CR, Galib PBJ, Prajapati PK (2012) Quantitative estimation of satva extracted from different stem sizes of Guduchi (Tinospora cordifolia (Willd.) Miers. J Pharm Sci Inno 1:38-40

Sharma R, Kumar V, Ashok BK, Galib R, Prajapati PK, Ravishankar B (2013a) Hypoglycemic and anti-hyperglycemic activity of Guduchi Satva in experimental animals. Pharmacol Study 34:417-420

Sharma R, Prajapati PK, Dhiman K, Shukla VJ (2013b) Quality control evaluation of Guduchi Satva (solid aqueous extract of Tinospora cordifolia (Willd.) Miers): an herbal formulation. Int J Green Pharm 7:258-263

Sharma R, Amin H, Galiba PPK (2013c) Seasonal variations in physicochemical profiles of Guduchi Satva (starchy substance from Tinospora cordifolia [Willd.] Miers). J Ayurveda Integr Med 4:193-197

Sharma R, Amin H, Galiba PPK (2013d) Validation of standard manufacturing procedure of Gudūcī sattva (aqueous extract of Tinospora cordifolia (Willd.) Miers) and its tablets. Anc Sci Life 33:27-34

Sharma R, Amin H, Galiba PPK (2014) Therapeutic Vistas of Guduchi (Tinospora cordifolia): a medico-historical memoir. J Res Educ Indian Med 20:121-135
Sharma R, Amin H, Prajapati PK (2015a) Physicochemical evaluation of Satva extracted from male and female plants of Guduchi (Tinospora cordifolia (Willd.) Miers). J Ayu Herb Med 1:13-16

Sharma R, Amin H, Prajapati PK (2015b) Physicochemical evaluation of male and female plants of Guduchi (Tinospora cordifolia (Willd.) Miers). The J Phytopharmacol 4:116-120

Sharma R, Amin H, Galiba PPK (2015c) Antidiabetic claims of Tinospora cordifolia (Willd.) Miers: critical appraisal and role in therapy. Asian Pac J Trop Biomed 5:68-78

Singh SS, Pandey SC, Srivastava S, Gupta VS, Patro B, Ghosh AC (2003) Chemistry and medicinal properties of Tinospora cordifolia (guduchi). Ind J Pharmacol 35:83-91

Usmani G, Shah SN, Chawhaan PH, Mishra Y, Mandal AK (2015) Estimation of genetic parameters and association of growth characters in Tinospora cordifolia (Willd.) Miers Ex Hook. F. \& Thoms. Ind for 141:941-945

Vasanthkumar S, Arun HS (2020) Efficacy of natural compounds from Tinospora cordifolia against SARS-CoV-2 protease, surface glycoprotein and RNA polymerase. BEMS Reports 6:6-8

Vellingiri B, Jayaramayya K, Iyer M, Narayanasamy A, Govindasamy V, Giridharan B, Ganesan S, Venugopal A, Venkatesan D, Ganesan H, Rajagopalan K, Rahman PKSM, Nachimuthu SK, Subramaniam MD (2020) COVID-19: a promising cure for the global panic. Sci Total Environ 725:138277

Wang S, Gao W, Jia W, Xiao P (2006) Crystallography, morphology and thermal properties of starches from four different medicinal plants of Fritillaria species. Food Chem 96:591-596

Wang S, Yu J, Gao W, Liu H, Xiao P (2007a) New starches from traditional Chinese medicine (TCM)- Chinese yam (Dioscorea opposita Thunb.) cultivars. Carbohydr Res 341:289-293

Wang S, Yu J, Gao W, Pang J, Yu J, Xiao P (2007b) Characterization of starch isolated from Fritillaria Traditional Chinese Medicine (TCM). J Food Eng 80:727-734

Publisher's Note Springer Nature remains neutral with regard to jurisdictional claims in published maps and institutional affiliations. 